\title{
New effective shape for the road covering
}

\author{
Kirill Voinov* \\ ITMO University, Saint-Petersburg, Russia
}

\begin{abstract}
There are too many transport/vehicles in a city/town at the present time (motor cars, lorries, buses, trolleybuses, dump trucks, ambulances, and another special machinery. Working in our cities/towns they give us three main negative factors, namely: exhaust carcinogenic gases, noise and ruts/ditches from tyres and the definite dangerous for people. In this article we plan to discuss and solve the problem connected only with the ruts and are ready to offer the new way how to reduce the rate of wear and tear for the road asphalt covering in those places where tyres are often rolling. For this purpose, the shapes both for the heavy roller and for the road covering were changed.
\end{abstract}

\section{Introduction}

There is not any information in here about how to effective delete the carcinogenic gases which are flying out from the pipes/chimneys of our works, factories, boiler-houses and so on because of this important problem was solved some months ago and was published as well [1-6].

That's why the gist of the investigations joined with the rational profile for the road covering will be demonstrated below.

It is common knowledge that many ruts will be on the places where many tyres are going every day on the definite zones. Sometimes the depth of the rut is about 55 millimetres, though the standard for the new asphalt covering demands to have roughness not more than $7 \mathrm{~mm}$. If periodically there are such big depth of the ruts, it disturbs both for a passer-by and for the vehicles. Moreover, some water will fill these ruts and tyres will splash it on the people. If there is rather cold weather, then the water can turn into the slippery ice. In this case the weakbeholder persons can fall and get any serious trauma. At last, for each vehicle such ice-covered ground is a great problem too.

If these depth ruts appear, the repair team/workers must cut asphalt, using special equipment, recover the movement for the many vehicles and create the inconveniences for the people.

\section{Text}

To avoid these problems and increase the term of good operation for the road asphalt coverings it is needed to change both the profile of the road and correct the shape of the roller (Figures 1 and 2).

The raising of this new profile for the road coating is not more than $5 \mathrm{~mm}$. This shape is a trapezium. Each lateral sides of these trapeziums have the angle of a slope not more than $15^{\circ}$. It doesn't create any problems for the vehicles which want to make a turning (for example, into the courtyard). This shape of a road doesn't intend for the high speed of movement for vehicles. To get such form of the road the new shape of roller must be used (Figure 2).

Using such shape of this heavy roller the new profile of the road will be got. These raisings on the $5 \mathrm{~mm}$ help to increase the common term of operation essentially for such asphalt covering (or with another type of covering material).
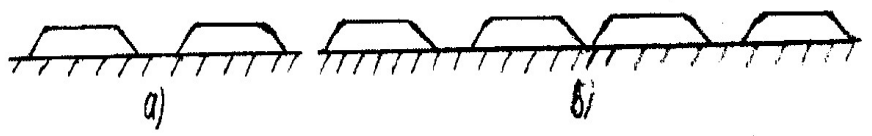

Figure 1. Profiles of the road asphalt coverings: a) one-way route; b) two-ways routes which have the dividing line between of the two routes

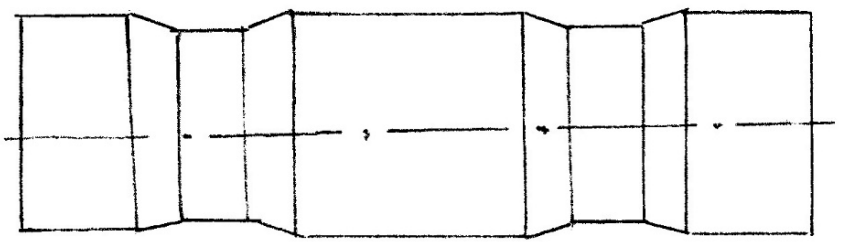

Figure 2. Profile of the new heavy roller

The point is that the moment when the noticeable wear and tear will be obtained (in $10 \mathrm{~mm}$ instead of 5 or $7 \mathrm{~mm}$ ) increases the term of operation approximately till seven as large as the model experiments had shown.

The real term of the operation for the new profile of the road covering will be depended upon the next factors:

- how many vehicles go along this road;

- the velocity of movement;

- load on the per metre run;

- types of tyres;

- strength and structure of this new profile;

${ }^{\star}$ Correspondence to: kirill voinov, ITMO University, Saint-Petersburg, Russia, E-mail: forstar@mail.ru

Key words: road asphalt covering, ruts, shape of roller

Received: September 26, 2019; Accepted: October 13, 2019; Published: October 18,2019 
- resistance of this profile to the action from the environment and so on.

Naturally, this profile doesn't intend for the high-speed route.

Note: there is no problem to make such profile for the heavy roller. Moreover, the applied technology for the covering essentially will not be changed also. At last, this method can accelerate the period of repairing and it can be applied only in local place where there are these ruts (don't touch the all width of the road.

\section{Conclusion}

The new and effective method how it is needed to change the profile of the road and the shape of the roller is represented in here. It permits to increase the term of normal operation for the many roads, save money, facilitate the repair and the time connected with such procedure.

\section{References}

1. Voinov KN (2014) Patent RU: 2541959: Profile of the asphalt-concrete covering for the road.

2. https://russianpatents.com/patent/260/2600580.html

3. Johnson, Carolyn Y (2009) Poison gas may carry a medical benefit.

4. http://www.findpatent.ru/patent/211/2110318.html. CFindPatent.ru, 2012-2017.

5. Patent RU №2504612, E01C7/18. Road clothes.

6. Patent RU №2119465, E01C7/18, Asphalt-concrete mixture

7. Patent RU №2332535, МПК E01C 7/18; Bitumen-ceramic composition. 27.08.2008.

Copyright: $\odot 2019$ Voinov K. This is an open-access article distributed under the terms of the Creative Commons Attribution License, which permits unrestricted use, distribution, and reproduction in any medium, provided the original author and source are credited. 